\title{
What Effects on Stature and Weight Growth of newborns of mothers using Jadelle $₫$ Implants in the Immediate Postpartum? Senegal's experience
}

\author{
Moussa Diallo*, Astou Coly Niassy Diallo, Abdoul Aziz Diouf, Aminata Niass, Omar Gassama, Mame Diarra \\ Ndiaye Gueye and Alassane Diouf \\ Centre Hospitalier National de Pikine, Cis Ex Camp de Thiaroye, Sénégal
}

Submission: January 17, 2019 ; Published: July 18, 2019

*Corresponding author: Moussa Diallo, Centre Hospitalier National de Pikine, Cis Ex-Camp de Thiaroye, Sénégal

\begin{abstract}
The aim of this study was to evaluate the side effects of Jadelle® implants in the immediate postpartum and study their impact on the metabolism and growth of the newborn and infant.

Materials and Method: To do this, we inserted the implants at two different postpartum period : first, between the first and the seventh day for the immediate postpartum period (IPP) group ; second, between the 45th and the 3rd postpartum months for the late postpartum (LPP) group. The variables studied were birth route, weight at birth, quality of milky climb, pregnancy term at time of delivery, complaints, the weight, height, head, brachial, thoracic and cranial perimeters and their evolution over time.

Results : In both groups, full-term infants were the most numerous. In the IPP group, however, the proportion of premature babies was slightly higher than in the other group. In both groups, the upper lane (caesarean section) was the most frequently reported delivery route, $86 \%$ for the late postpartum group and $70 \%$ for the immediate postpartum group. In the IPP group, insertions took place on the third postpartum day for the majority of patients, and were all done before the seventh day. The LPP group took place at six weeks and rarely more than two months (four cases only). The mean weights of the two groups were not very different. They were $2920 \mathrm{~g}$ and $2930 \mathrm{~g}$ respectively for the immediate postpartum group and the late postpartum group. This was not the case for the maxima of $4400 \mathrm{~g}$ and $5000 \mathrm{~g}$ respectively for the IPP and LPP group. By correcting this discrepancy, there is no statistically significant difference in infant growth. The same is true for newborns of low birth weight. Given the low sample size after adjusting the data, caution is required in interpreting these results. we found that the metabolism of the liver was not disturbed by the product.
\end{abstract}

Conclusion: Our results are encouraging to further promote contraception in the immediate postpartum period in developing countries and thus reach a wide range of users. We can therefore say that the side effects are not different during this period and largely are also tolerated.

Keywords: Immediate Postpartum contraception progestogen

\section{Introduction}

In sub-Saharan Africa, maternal mortality remains at a worrying level. Every year more than 500,000 women lose their lives by giving birth. In Senegal, it is currently 392 per 100,000 live births [1]. Birth spacing has been strongly advised by world health organization (WHO) to reduce these alarming rates [2]. Immediate postpartum can be widely depicted by high-profile hospitals such as ours to reduce missed opportunities. Indeed, most of the patients are referred to other structures. Reducing unmet need for contraception especially after childbirth is a major challenge in sub-Saharan Africa. This period is undoubtedly more delicate for a prescription of hormonal contraceptives. Because of this, the enzymatic immaturity of the fetal liver where a metabolism of the products used. This period can be considered a difficult contraception because of neonatal hepatic immaturity. The objective of this study is to assess the safety of levonorgestrel in the newborn and infant during the first six months of life.

\section{Patients and Methods}

We included in this study all patients who had a natural birth or caesarean delivery in our service during the collection period, who accepted the contraceptive method by Jadelle $®$ implants after counseling and who were not contraindicated for this method. We don't included all patients with contraindications for the use of hormonal contraception or breast-feeding and newborns with a severe condition and finally patients who did not consent to the use of the method. The insertion was made after delivery before returning home or during post-natal consultations. It occurred 
between the first and the seventh day of the postpartum period for the immediate postpartum period (IPP) group and between the 45 th and the 3 rd postpartum months for the late postpartum (LPP) group at the internal side of the arm (of the non-dominant member). The procedue was practiced by the same practitioner. From the date of insertion, patients were monitored on a monthly basis. During the post-insertion consultations, patients were completely clinical examinated. All the patients were examined by the same practitioner. The variables studied were age, childbirth, caesarean section, quality of milky rise, age last child, contraception, pregnancy term at time of delivery, complaints, weight. At each consultation, clinical (weight, height, perimeter, brachial and thoracic) and biological (transaminases, bilirubin) constants were recorded monthly and quarterly respectively. The data collected was processed using the EXCEL software for Windows Office 2010 for the global computerization of data and the production of tables and figures and SPSS 17.0 for Windows for the calculation of means and tests of significance.

\section{Résult}

\section{Term of pregnancy at childbirth}

Table 1: Distribution of newborns by term at birth.

\begin{tabular}{|c|c|c|c|}
\hline \multirow{2}{*}{ S.No } & \multirow{2}{*}{ Term of Pregnancy at Childbirth } & \multicolumn{2}{|c|}{ Groups } \\
\cline { 3 - 4 } & & LPP & IPP \\
\hline 1 & Prematures newborns & $2(4 \%)$ & $6(12 \%)$ \\
\hline 2 & Full term & $48(96 \%)$ & $42(84 \%)$ \\
\hline 3 & Term overrun & 0 & $2(4 \%)$ \\
\hline
\end{tabular}

Due to the absence of ultrasound dating of the pregnancy and the date of the last precise menstruations, the precise terms of the pregnancies at the time of delivery could not be specified. The subjective criterion used was the clinical examination of the newborn at birth, the birth weight and the presumed term given by the mother. In both groups, full-term infants were the most numerous. In the IPP group, however, the proportion of premature babies was slightly higher than in the other group (Table 1).

\section{Delivery route}

In both groups, the caesarean section was the most frequently reported delivery route, $86 \%$ for the late postpartum group and $70 \%$ for the immediate postpartum group. There was no significant difference between the two groups ( $\mathrm{p}=0.53)$.

\section{Period of insertion of the implants}

In the IPP group, insertions took place on the third postpartum day for the majority of patients, and were all done before the seventh day. The LPP group took place at six weeks and rarely more than two months (four cases only).

\section{Birth weight}

The mean weights of the two groups were not different. They were $2920 \mathrm{~g}$ and $2930 \mathrm{~g}$ respectively for the immediate postpartum group and the late postpartum group. This was not the case for the maxima of $4400 \mathrm{~g}$ and $5000 \mathrm{~g}$ respectively for the IPP and LPP group (Figure 1\&2).

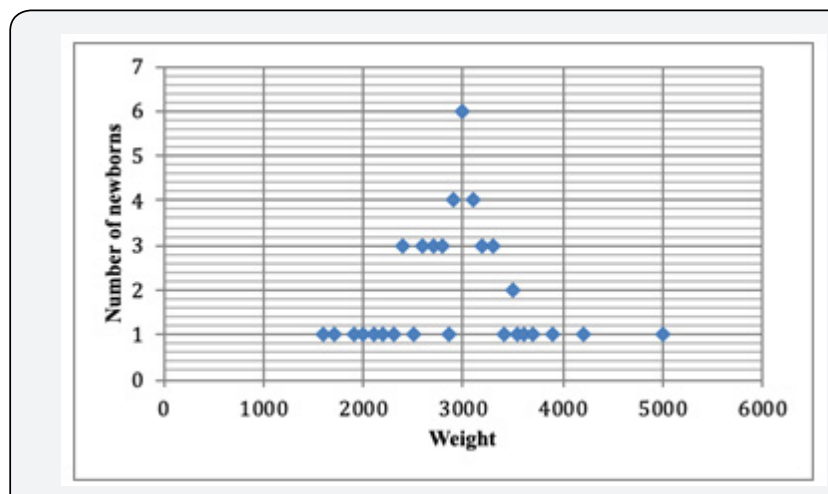

Figure 1: Distribution of birth weights: Late postpartum Group.

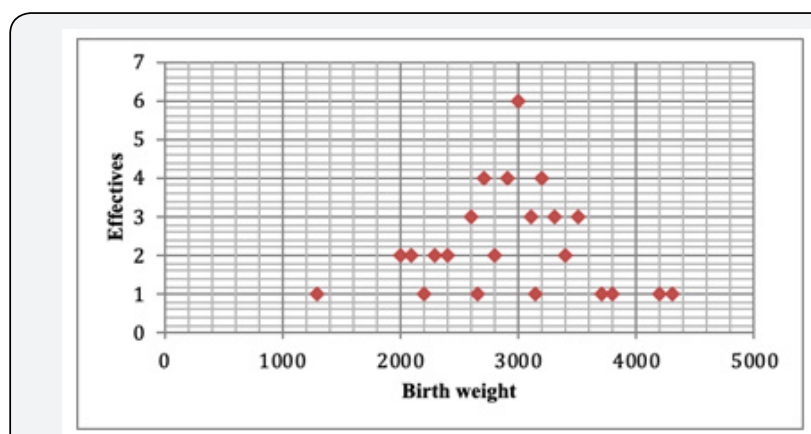

Figure 2: Distribution of birth weights: Immediate postpartum Group.

\section{Breast feeding}

All our patients had initially opted for exclusive breastfeeding for the first six months. When the Jadelle ${ }^{\circledR}$ implants were inserted, the milky rise was considered satisfactory, as was the post-natal consultation for all patients.

\section{Evolution of weight gain}

Table 2: Evolution of the average weight of newborns.

\begin{tabular}{|c|c|c|c|c|c|}
\hline \multirow{2}{*}{ S.No } & \multirow{2}{*}{$\begin{array}{c}\text { Périods of } \\
\text { Visits }\end{array}$} & \multicolumn{2}{|c|}{$\begin{array}{c}\text { Average Weight (G) } \\
\text { LPP }\end{array}$} & \multicolumn{2}{c|}{$\begin{array}{c}\text { Average Weight } \\
\text { Gain (G) }\end{array}$} \\
\cline { 3 - 6 } & & IPP & LPP & IPP \\
\hline 1 & Visit 1 & 6940 & 5800 & 1096 & 1214 \\
\hline 2 & Visit 2 & 7589,58 & 6838,78 & 650 & 1039 \\
\hline 3 & Visit3 & 8264,44 & 7585,71 & 675 & 747 \\
\hline 4 & Visit 4 & 8990,89 & 8291,49 & 726 & 706 \\
\hline 5 & Visit 5 & 9660 & 9146,34 & 669 & 855 \\
\hline
\end{tabular}

Taken as a whole, neonates did not differ in the change in infant weight as a function of time if the weight difference was taken into account for children in the late postpartum group present at recruitment. Mean monthly weight gain ranged from $706 \mathrm{~g}$ to $1214 \mathrm{~g}$ for IPP group babies, and from 669g to $1096 \mathrm{~g}$ for the LPP group; with a respective average weight gain of $912 \mathrm{~g}$ and $763 \mathrm{~g}$ (Table 2). By correcting this discrepancy, there is no statistically significant difference in infant growth. The same is true for newborns of low birth weight. Given the low sample size after adjusting the data, caution is required in interpreting these results. The weight at the first consultation is taken as a reference. For newborns with low birth weight, weight gain was steady and faster 
than that of eutrophic newborns at birth. In the IPP group, the mean weight at first visit was 2083.33g and 8840.00g at the last, resulting in an average monthly gain of $1126.16 \mathrm{~g}$. For the LPP group, the mean weight at the first visit was $2400 \mathrm{~g}$ and $7300 \mathrm{~g}$ at the last, giving an average monthly weight gain of $806.66 \mathrm{~g}$ (Table 3).

Table 3: Evolution of average weight over time of newborns with low birth weight.

\begin{tabular}{|c|c|c|c|c|}
\hline \multirow{2}{*}{ Average Weight } & \multicolumn{2}{|c|}{ Average } & \multicolumn{2}{c|}{ Monthly Average Gain } \\
\cline { 2 - 5 } & LPP & IPP & LPP & IPP \\
\hline At birth & 2400 & 2083,33 & 0 & 0 \\
\hline Visit 1 & 3850 & 3483,33 & 1450 & 1400,00 \\
\hline Visit 2 & 4900 & 4933,33 & 1050 & 1450,00 \\
\hline Visit3 & 5500 & 6166,67 & 600 & 1233,34 \\
\hline Visit 4 & 6300 & 7450 & 800 & 1283,33 \\
\hline Visit 5 & 6500 & 7820 & 200 & 370 \\
\hline Visit 6 & 7300 & 8840 & 800 & 1020,00 \\
\hline
\end{tabular}

\section{Evolution of the infants height}

Table 4: Evolution of the infants height.

\begin{tabular}{|c|c|c|c|c|}
\hline \multirow{2}{*}{ Periods } & \multicolumn{2}{|c|}{ Average Height (Cm) } & \multicolumn{2}{c|}{ Average Height Gain $\mathbf{( C m )}$} \\
\cline { 2 - 5 } & LPP & IPP & LPP & IPP \\
\hline Visit 2 & 62,9 & 59,45 & 3,61 & 4,45 \\
\hline Visit3 & 65,13 & 62,53 & 2,23 & 3,08 \\
\hline Visit 4 & 67,73 & 65,4 & 2,6 & 2,87 \\
\hline Visit 5 & 69,53 & 68,53 & 1,8 & 3,13 \\
\hline Visit 6 & 71,47 & 70,65 & 1,94 & 2,12 \\
\hline
\end{tabular}

Table 5: Evolution of the average height of newborns with low weight at birth.

\begin{tabular}{|c|c|c|c|c|}
\hline \multirow{2}{*}{ Periods } & \multicolumn{2}{|c|}{ Average Height (Cm) } & \multicolumn{2}{c|}{ Average Height Gain (Cm) } \\
\cline { 2 - 5 } & LPP & IPP & LPP & IPP \\
\hline Visit 2 & 60,5 & 56 & 6 & 4,67 \\
\hline Visit 3 & 61,5 & 60,67 & 1 & 4,67 \\
\hline Visit 4 & 63,7 & 63,67 & 2,2 & 3 \\
\hline Visit 5 & 65,1 & 66,2 & 1,4 & 2,53 \\
\hline Visit 6 & 69 & 68,2 & 3,9 & 2 \\
\hline
\end{tabular}

In the immediate postpartum group, the mean monthly gain of $1.98 \mathrm{~cm}$ for all newborns combined. For the late postpartum group, it was $2.60 \mathrm{~cm}$. The two evolutionary curves show a steady rise in the size of the first to the sixth post-natal visit. The evolutionary curves of low birth weight babies in the two groups are broadly similar, as they are all ascending from the first to the sixth postnatal consultation (Table 4\&5).

\section{Evolution of the cranial perimeter}

Infants in the immediate postpartum group had an average cranial perimeter of $37.84 \mathrm{~cm}$ at the first consultation and $44.52 \mathrm{~cm}$ at the last. Those of the other group had an average of $39.14 \mathrm{~cm}$ at the first consultation and $45.32 \mathrm{~cm}$ at the last. For newborns of low birth weight have also experienced a growing ascent (Table 6\&7).
Table 6: Evolution of the cranial perimeter.

\begin{tabular}{|c|c|c|c|c|}
\hline \multirow{2}{*}{ Periods } & \multicolumn{2}{|c|}{$\begin{array}{c}\text { Average of Cranial Pe- } \\
\text { rimeter (Cm) }\end{array}$} & \multicolumn{2}{|c|}{$\begin{array}{c}\text { Average Monthly Gain } \\
\text { (Cm) }\end{array}$} \\
\cline { 2 - 5 } & LPP & IPP & LPP & IPP \\
\hline Visit 2 & 41,44 & 39,84 & 2,3 & 2 \\
\hline Visit 3 & 42,87 & 41,52 & 1,43 & 1,68 \\
\hline Visit 4 & 43,3 & 42,9 & 0,43 & 1,38 \\
\hline Visit 5 & 44,53 & 44,52 & 1,23 & 1,62 \\
\hline Visit 6 & 45,32 & 51,82 & 0,79 & 0,73 \\
\hline
\end{tabular}

Table 7: Evolution of the average cranial perimeter of newborns with low weight at birth.

\begin{tabular}{|c|c|c|c|c|}
\hline \multirow{2}{*}{ Periods } & \multicolumn{2}{|c|}{$\begin{array}{c}\text { Average of Cranial Pe- } \\
\text { rimeter (Cm) }\end{array}$} & \multicolumn{2}{|c|}{$\begin{array}{c}\text { Average Monthly Gain } \\
\text { (Cm) }\end{array}$} \\
\cline { 2 - 5 } & LPP & IPP & LPP & IPP \\
\hline Visit 2 & 37 & 38 & 0,5 & 2,2 \\
\hline Visit 3 & 37,5 & 39 & 0,5 & 1 \\
\hline Visit 4 & 43 & 42 & 5,5 & 3 \\
\hline Visit 5 & 44 & 42,6 & 1 & 0,6 \\
\hline Visit 6 & 44 & 43,25 & 0 & 0,65 \\
\hline
\end{tabular}

\section{Evolution of the thoracic perimeter}

The mean thoracic perimeter of infants in the immediate postpartum group at the first visit was $36.71 \mathrm{~cm}$ and $44.37 \mathrm{~cm}$ at the last. For those of the late postpartum it was $39.3 \mathrm{~cm}$ at the first visit and $45.71 \mathrm{~cm}$ at the sixth. But on the curves of comparative evolution, this difference does not appear, the curves being almost confounded. For newborns of low birth weight taken separately, those of the immediate postpartum had an average of $32.67 \mathrm{~cm}$ at the first consultation and $44 \mathrm{~cm}$ at the last. As for those in the other group, the average at the first consultation was $32 \mathrm{~cm}$ and $42 \mathrm{~cm}$ at the last. There is also no significant difference in the chest perimeter curves of premature infants. There is a steady and continuous increase from the first to the sixth postnatal consultation. The data from the first consultation were taken as references.

\section{Biological Parameters}

\section{Aspartate aminotransferase rate}

The mean transaminase level of all late postpartum infants was $44 \mathrm{IU}$ at the first consultation, $35 \mathrm{IU}$ at the third and $16 \mathrm{IU}$ at the last consultation. There are, however, maxima of 117, 90 and 77. In the immediate postpartum group, these mean rates were respectively 41.89, 42.26 and $38.82 \mathrm{IU} / \mathrm{L}$. However, maximum rates of 134, 80 and 100 IU were observed in the first, second and third consultations. On the evolution curves, there is a gradual decrease in average rates over time.

\section{Alanine aminotransferase rate}

The mean rate of transaminases in newborns in the late postpartum group at the first prenatal visit was $20.6591 \mathrm{IU} / \mathrm{L}$, $16.74 \mathrm{IU} / \mathrm{L}$ at the third consultation and $20.88 \mathrm{IU} / \mathrm{L}$ at the sixth consultation. Taking 40UI/ L as the upper limit of reference, $6 \%$ of infants, including those born prematurely or with a low birth 
weight, had a high ALT transaminase level but never doubled this level. These rates were 44, 52 and 68 IU/L. In the immediate postpartum group, the mean rates at the $1 \mathrm{st}, 2 \mathrm{nd}$ and 6 th post-natal consultations were $26.90 \mathrm{IU} / \mathrm{L}, 26.63 \mathrm{IU} / \mathrm{L}$ and 23.64 IU/L. but six of the infants had high levels above 40 IU/L but did not double this rate. In the immediate postpartum group, mean ALT rates tended to decline gradually, which was almost the reverse of what was observed in the other group. In both groups, there were no abnormally high rates in low birth weight babies.

\section{Total bilirubin rate}

In the infants of the immediate postpartum group, the mean total bilirubin levels during the consultations were 2.0737, 0.6029 and $0.3488 \mu \mathrm{mol} / \mathrm{L}$ at the first, third and sixth consultations, respectively. In the late postpartum group, these same rates were $1.7243,0.6797,0.395 \mu \mathrm{mol} / \mathrm{L}$ at the three postnatal consultations. Since the normal total bilirubin level did not exceed $6 \mu \mathrm{mol} / \mathrm{L}$, none of the infants followed had pathological levels.

\section{Indirect bilirubin rate}

For indirect bilirubin, mean rates in the immediate postpartum group were $0.9955,0.4138$ and $0.325 \mu \mathrm{mol} / \mathrm{L}$ for the three postnatal visits. In the late postpartum group, these rates were respectively $0.7151,0.6259$ and $0.3536 \mu \mathrm{mol} / \mathrm{L}$, respectively; but with a maximum rate of $10.68 \mu \mathrm{mol} / \mathrm{L}$ at the first consultation. Evolution curves in both groups showed rates with a progressive decrease in postnatal follow-up, none of which had reached pathological value.

\section{Direct bilirubin rate}

In the immediate postpartum group, the mean rates at the three post-natal consultations were 1.029, 0.3644 and 0.2705 $\mu \mathrm{mol} / \mathrm{L}$. But high levels were noted with a maximum of 13.6 $\mu$ moles/L at the first. In the late postpartum group, the respective rates were $0.871,0.2784$ and $0.2257 \mu \mathrm{mol} / \mathrm{L}$. Here a maximum level of $10 \mu \mathrm{mol} / \mathrm{L}$ is also obtained at the following consultation. The curves of rates in both groups had a tendency to decrease as time went on.

\section{Discussion}

The need for immediate postpartum use of hormonal contraception during breastfeeding is a complex problem. Progestin-only implants (Norplant $\AA$, Jadelle $\AA$ and Implanon $\AA$ ) deliver a product that remains active after secretion into breast milk. But the proof of the deleterious effects of these steroids absorbed by the newborn exposed in the early days of the postpartum remains to be established.

\section{Clinical Parameters}

\section{Weight and height}

For patients in the IPP group, the minimum weight found at the first visit was $1300 \mathrm{~g}$ and the maximum weight was $4300 \mathrm{~g}$ with an average weight of $2920 \mathrm{~g}$. In the LPP group the extremes were $1600 \mathrm{~g}$ for the minimum and $5000 \mathrm{~g}$ for the maximum weight with an average of $2930 \mathrm{~g}$. The figures below provide information on the evolution of average weight and height of infants in both sexes compared to WHO standards (z-scores) (Figure 3\&4). Many studies have been conducted to evaluate the effect of hormones (including progesterone) in contraceptives on the quality of milder growth and neonatal growth [3-6]. All performed with an introduction after six weeks postpartum, they did not report deleterious effects on infant growth (Figure 5\&6).

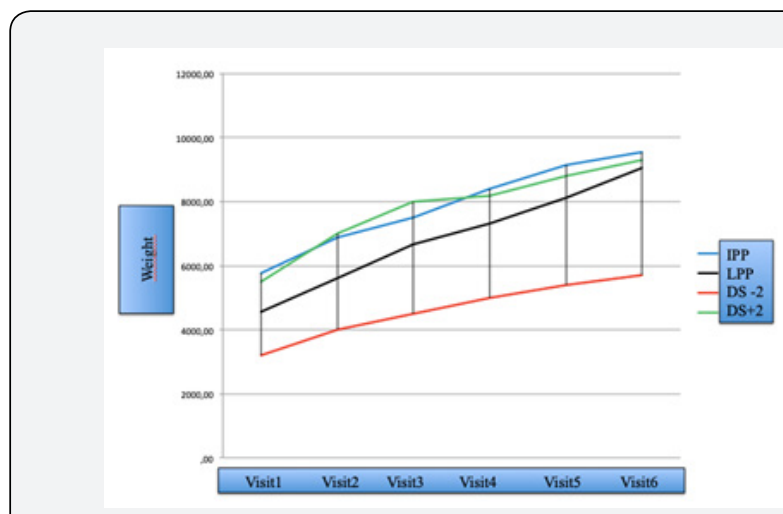

Figure 3: Evolution of the average weight of female (DS-2 : -2 standard deviations, DS+2 : + 2 standard deviations).

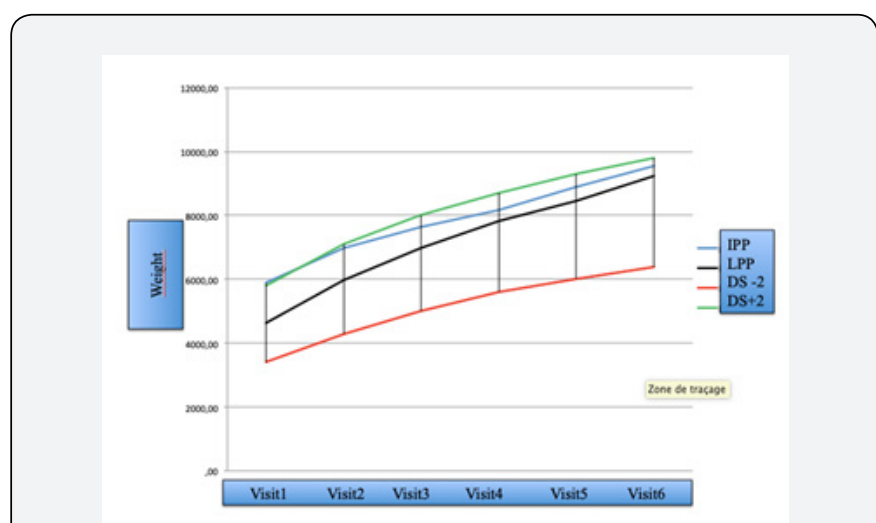

Figure 4: Evolution of average weight of male infants (DS-2 : -2 standard deviations, DS+2 : + 2 standard deviations).

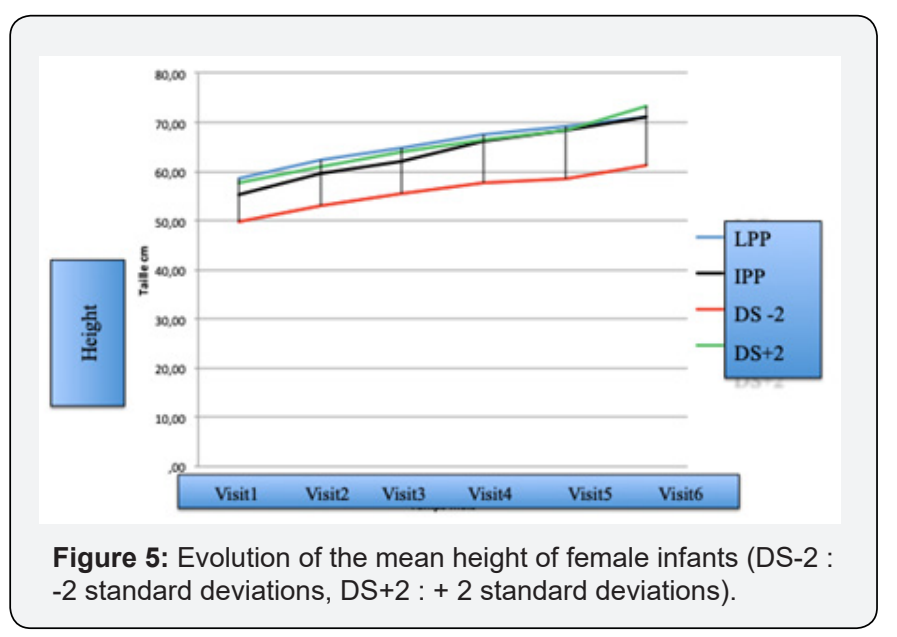

A study comparing the growth of infants of mothers on Norplant $₫$ inserted after six weeks postpartum on the one hand and copper IUD on the other hand showed no difference between the 
two groups [5]. The same is true for the levonorgestrel intrauterine device (Mirena ${ }^{\circledR}$ ) [7-9]. We can deduce that there is no difference between the two groups on the one hand and on the other hand with the WHO standards, and these data are consistent with those of the literature.

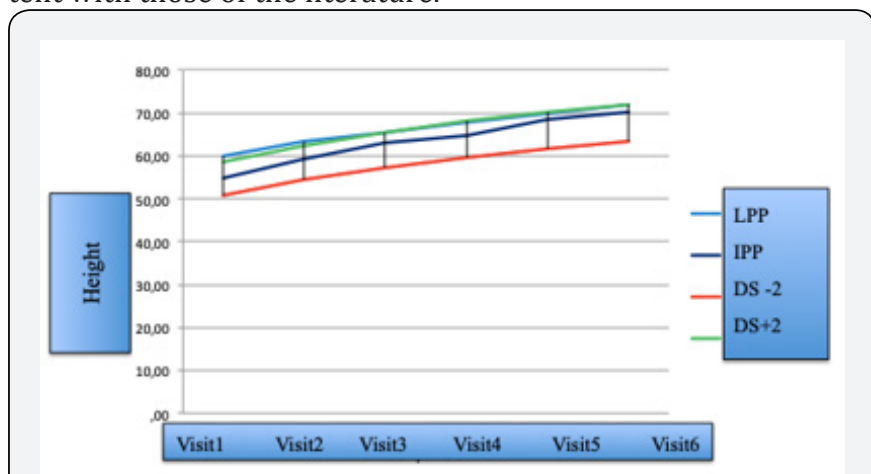

Figure 6: Evolution of the mean height of male infants (DS-2 : -2 standard deviations, DS+2: + 2 standard deviations).

Effect on Hepatic Metabolism

\section{Alanine and aspartate aminotransferases rates}

On the evolution curves there is a gradual decrease in average rates over time. Infants, having rates greater than or equal to twice the normal rate at the first visit, had no visible clinical manifestations and during control these rates normalized. There are no data available in the literature that took into account biological parameters. In both groups there are no abnormally high rates in low birth weight. There were no clinical manifestations in infants with high levels. No data from the literature is available to compare the results.

\section{Bilirubins rates (total, direct and indirect)}

The normal total bilirubin level should not exceed $6 \mu \mathrm{mol} / \mathrm{L}$, none of the infants followed, in this case had pathological levels. Rates evolution curves in both groups tended to decrease rates, initially high over time. This phenomenon could share the same mechanism of occurrence as neonatal jaundice. The evolution curves in both groups show rates with a progressive decreasing trend along the postnatal follow-up, and none of these rates had reached a pathological value. No data from the literature is available to compare the results.

\section{Conclusion}

In light of these findings, we can say that the early introduction of progestational contraception in the postpartum before returning home does not seem to alter the hepatic metabolism in normal neonates breastfed exclusively in the breast. And it would be prudent to avoid its use in case of pathological situation (liver disease, severe neonatal jaundice, fetal distress). To minimize the risk of disruption of hepatic metabolism, the examination of the newborn should be systematic.

\section{References}

1. Enquete Agence Nationale de la Statistique et de la Démographie (ANSD) Dakar, Sénégal (2012) Enquête Démographique et de Santé à Indicateurs Multiples Sénégal. MEASURE DHS ICF International Calverton M, USA, editor. Sénégal: Ministère de la Santé, de la Prévention et de l'Hygiène Familiale, USAID, UNICEF, UNFPA, CLM, Division SIDA, The global found; Fevrier, USA.

2. World Health Organization (1994) Task Force for Epidemiological Research on Reproductive Health. Special Programme of Research, Development and Research Training in Human Reproduction. Progestogen-only contraceptives during lactation: I Infant growth. Contraception 50: 35-53.

3. Wilde C, Addey C, Bryson J, Finch L, Knight C, et al. (1998) Autocrine regulation of milk secretion. Biochem Soc Symp 63: 81-90.

4. Ba M, Moreau J, Sokal D (1999) A 5-year clinical evaluation of Norplant implants in Senegal. Contraception 59: 377- 381.

5. Kappa N, Curtisb K, Nanda K (2010) Progestogen-only contraceptive use among breastfeeding women: a systematic review. Contraception 82(1): 17-37.

6. Schiappacasse V, Soledad D, Zepeda A, Alvarado R, Herreros C, et al. (2002) Health and growth of infant's breastfed by Norplant contraceptive implants users: a six-year follow-up study. Contraception 66(1): 57-65.

7. Truitt S, Fraser A, Grimes D, Gallo M, Schulz K, et al. (2003) Hormonal contraception during lactation: systematic review of randomized controlled trials. Contraception 68(4): 233-238.

8. Ayman H, Shaamash T, Gamal H, Sayed, Mostafa M, et al. (2005) A comparative study of the levonorgestrel-releasing intrauterine system MirenaR versus the Copper T380A intrauterine device during lactation: breast-feeding performance, infant growth and infant development. Contraception 72(5): 346-351.

9. Abdel-Aleem H, El-Sayed M, Abol-Oyoun, Shaaban MM, El-Saeed M, et al. (1996) The use of nomegestrol acetate subdermal contraceptive implant uniplant, during lactation. Contraception 54(5): 281-286.

Your next submission with Juniper Publishers
will reach you the below assets
- Quality Editorial service
- Swift Peer Review
- Reprints availability
- E-prints Service
- Manuscript Podcast for convenient understanding
- Global attainment for your research
- Manuscript accessibility in different formats
( Pdf, E-pub, Full Tsext, Audio)
- Unceasing customer service
Track the below URL for one-step submission
https://juniperpublishers.com/online-submission.php

